OPEN ACCESS

Edited by:

Renchao Zhou,

Sun Yat-sen University, China

Reviewed by:

Ludovic Duvaux,

University of Angers, France

Yue-Hong Yan,

Shanghai Chenshan Plant Science Research Center, CAS and Shanghai

Chenshan Botanical Garden, China

*Correspondence:

Shao-Qing Tang

shaoqing@mailbox.gxnu.edu.cn

Specialty section:

This article was submitted to

Evolutionary and Population Genetics,

a section of the journal

Frontiers in Plant Science

Received: 22 November 2016 Accepted: 19 April 2017 Published: 19 May 2017

Citation:

Wei S-J, Lu Y-B, Ye Q-Q and Tang S-Q (2017) Population Genetic

Structure and Phylogeography of Camellia flavida (Theaceae) Based on

Chloroplast and Nuclear DNA Sequences. Front. Plant Sci. 8:718.

doi: $10.3389 /$ fpls.2017.00718

\section{Population Genetic Structure and Phylogeography of Camellia flavida (Theaceae) Based on Chloroplast and Nuclear DNA Sequences}

\author{
Su-Juan Wei ${ }^{1,2}$, Yong-Bin Lu ${ }^{2}$, Quan-Qing Ye ${ }^{1,2}$ and Shao-Qing Tang ${ }^{1,2 *}$ \\ ${ }^{1}$ Key Laboratory of Ecology of Rare and Endangered Species and Environmental Protection, Ministry of Education, Guangxi \\ Normal University, Guilin, China, ${ }^{2}$ College of Life Science, Guangxi Normal University, Guilin, China
}

Camellia flavida is an endangered species of yellow camellia growing in limestone mountains in southwest China. The current classification of $C$. flavida into two varieties, var. flavida and var. patens, is controversial. We conducted a genetic analysis of C. flavida to determine its taxonomic structure. A total of 188 individual plants from 20 populations across the entire distribution range in southwest China were analyzed using two DNA fragments: a chloroplast DNA fragment from the small single copy region and a single-copy nuclear gene called phenylalanine ammonia-lyase (PAL). Sequences from both chloroplast and nuclear DNA were highly diverse; with high levels of genetic differentiation and restricted gene flow. This result can be attributed to the high habitat heterogeneity in limestone karst, which isolates $C$. flavida populations from each other. Our nuclear DNA results demonstrate that there are three differentiated groups within C. flavida: var. flavida 1, var. flavida 2, and var. patens. These genetic groupings are consistent with the morphological characteristics of the plants. We suggest that the samples included in this study constitute three taxa and the var. flavida 2 group is the genuine $C$. flavida. The three groups should be recognized as three management units for conservation concerns.

Keywords: Camellia flavida, phylogeography, species delimitation, genetic differentiation, habitat heterogeneity, conservation implication

\section{INTRODUCTION}

Camellia (Theaceae) species with yellow flowers, known as yellow camellia, grow in parts of south China and north Vietnam. Studies have reported 10-16 species in China (Chang and Ren, 1998; Ming and Bartholomew, 2007). These plants are mainly distributed in Guangxi, with only a few reaching Guizhou and Yunnan Province (Chang and Ren, 1998; Liang, 2007). Most species of yellow camellia in China have restricted distributions. Yellow camellia frequently grows in primary forests, as understory shrubs or small trees, but they can also be found among secondary forests and shrubs that have suffered from deforestation. Some species grow in calcareous soil, and others are found in acidic soil. No known species naturally grows in both calcareous and acidic soil. Calcareous species are usually found at the bottom of depressions or on slopes in areas with high humidity and shade (Su and Mo, 1988; Su, 1994).

Yellow camellia are valuable ornamental plants and genetic resources for breeding. Moreover, yellow camellia leaves and flowers are used in traditional Chinese medicine and commercially 
available teas (He et al., 2016). Thousands of hectares are dedicated to growing yellow camellia for a variety of products. Excessive collecting from natural populations for ornamental planting has caused the destruction of wild populations, and all yellow camellia species were recently categorized as critically endangered, endangered, or near endangered species in the China Biodiversity Red List (data available at http://english.mep. gov.cn).

The karst area in southwestern China is the largest karst ecosystem in the world (Yuan, 1991; Wang et al., 2004). The karst is home to many plant species and contributes significantly to the floristic diversity of China, but many species are threatened (Orme et al., 2005; Hao et al., 2014; Luo et al., 2016). Camellia flavida Chang, one of yellow camellia, is a typical limestone species distributed in this area. It was first reported by Chang (1981), who found it in Longzhou. Since then, several new yellow camellia species collected from limestone mountains in the area have been described, including Camellia longgangensis (Liang and Mo, 1982), Camellia longgangensis var. grandis (Liang and Mo, 1982), Camellia ptilosperma (Liang, 1984), and Camellia longruiensis (Liang, 1993). These species are morphologically similar and were revised and treated as synonyms of C. flavida by Ming and Zhang (1993), Ming (2000), and Ming and Bartholomew (2007); however, Chang and Ren (1998) treated C. longgangensis as a synonym of C. flavida and classified the other three taxa as a distinct species, C. grandis (Table 1). Based on the herbarium specimens collected from limestone hills in Fusui and Wuming, adjacent to Longzhou, another four yellow camellia taxa were described, including Camellia longgangensis var. patens (Mo and Zhong, 1985), Camellia quinqueloculosa (Mo and Zhong, 1985), Camellia multipetala (Liang, 1993), and Camellia wumingensis (Liang, 1993). These were all treated as varieties of C. flavida (i.e., var. patens) according to the classification by Ming and Bartholomew (2007); however, Chang and Ren (1998) treated C. quinqueloculosa as a synonym of Camellia aurea and did not address the other three taxa (Table 1). Hence, there is disagreement regarding the classification of C. flavida among Camellia researchers.

TABLE 1 | Previous researchers' classifications of C. flavida.

\begin{tabular}{|c|c|c|c|}
\hline $\begin{array}{l}\text { First attributed } \\
\text { species name }\end{array}$ & $\begin{array}{l}\text { Chang, 1991; } \\
\text { Chang and } \\
\text { Ren, } 1998\end{array}$ & $\begin{array}{l}\text { Ming and } \\
\text { Bartholomew, } 2007\end{array}$ & Ye and Xue, 2013 \\
\hline C. flavida & C. flavida & C. flavida & - \\
\hline C. longgangensis & C. flavida & C. flavida var. flavida & C. longgangensis \\
\hline $\begin{array}{l}\text { C. longgangensis } \\
\text { var. grandis }\end{array}$ & C. grandis & C. flavida var. flavida & - \\
\hline C. ptilosperma & C. grandis & C. flavida var. flavida & C. longgangensis \\
\hline C. longruiensis & - & C. flavida var. flavida & C. longgangensis \\
\hline $\begin{array}{l}\text { C. longgangensis } \\
\text { var. patens }\end{array}$ & - & C. flavida var. patens & C. quinqueloculosa \\
\hline C. quinqueloculosa & C. aurea & C. flavida var. patens & C. quinqueloculosa \\
\hline C. multipetala & - & C. flavida var. patens & C. quinqueloculosa \\
\hline C. wumingensis & - & C. flavida var. patens & C. wumingensis \\
\hline
\end{tabular}

-, the species has not been treated by the researcher.
Ye and Xue (2013) studied the morphological characteristics of the flowers, fruits, seeds, and leaves of the taxa that had been reduced to $C$. flavida, and the results suggested that (1) C. ptilosperma and C. longruiensis should be considered synonyms of C. longgangensis, (2) C. longgangensis var. patens and $C$. multipetala should be classified as a synonym of $C$. quinqueloculosa, and (3) C. wumingensis is an independent species (Table 1).

The size of the natural population of C. flavida, especially its variant $C$. flavida var. patens, has declined dramatically due to illegal transplanting. Thus, its distribution has become significantly fragmented. C. flavida has been listed as an endangered species in the China Species Red List (Wang and Xie, 2004) and China Biodiversity Red List (data available at http://english.mep.gov.cn). Effective conservation of endangered species requires accurate taxonomic classification, and incorrect taxonomy can lead to erroneous conservation decisions (Hong, 2016; Su et al., 2017). Genetic diversity is also critical to both the long-term survival of populations or species and their evolutionary potential (Frankel, 1974; Pérez-Espona and Consortium, 2017). Analysis of the spatial distribution of the genetic diversity of a species can help identify distinct genetic groups (Allendorf and Luikart, 2007; Mkare et al., 2017). However, the classification of C. flavida is still controversial, and the genetic diversity and population structure are not yet understood.

Molecular genetics analyses can help resolve the taxonomic uncertainties and define management units within species (Frankham et al., 2002), and therefore, develop an efficient strategy for conservation. In the present study, we conducted phylogeographic and population genetic analyses of C. flavida using both chloroplast DNA (cpDNA) and a single-copy nuclear gene. Plastid and nuclear markers are frequently used in phylogeographic and population genetic studies, as they present different features (Avise, 2009; Leuzinger et al., 2015). By combining these two types of markers, we aimed to (1) determine the population genetic structure and phylogeographic patterns of C. flavida, (2) clarify the species classification and boundaries, and (3) propose recommendations for guiding future preservation actions.

\section{MATERIALS AND METHODS Sample Collection Strategy and DNA Isolation}

Samples were collected for this study using the taxonomic classification of Ming and Bartholomew (2007), which was based on leaves and flowers. The 188 samples included in the analysis were collected from 20 wild populations from almost the entire geographical range of the species in southwest Guangxi, China (Figure 1). Ten individuals were selected per population. For those populations (BZ, SG, and NXS) containing fewer than 10 individuals, samples were collected from all available plants (Table 2). For each population, fresh leaves were randomly collected and dried in silica gel. Genomic DNA was extracted from dried leaves using a modified cetyl trimethylammonium 


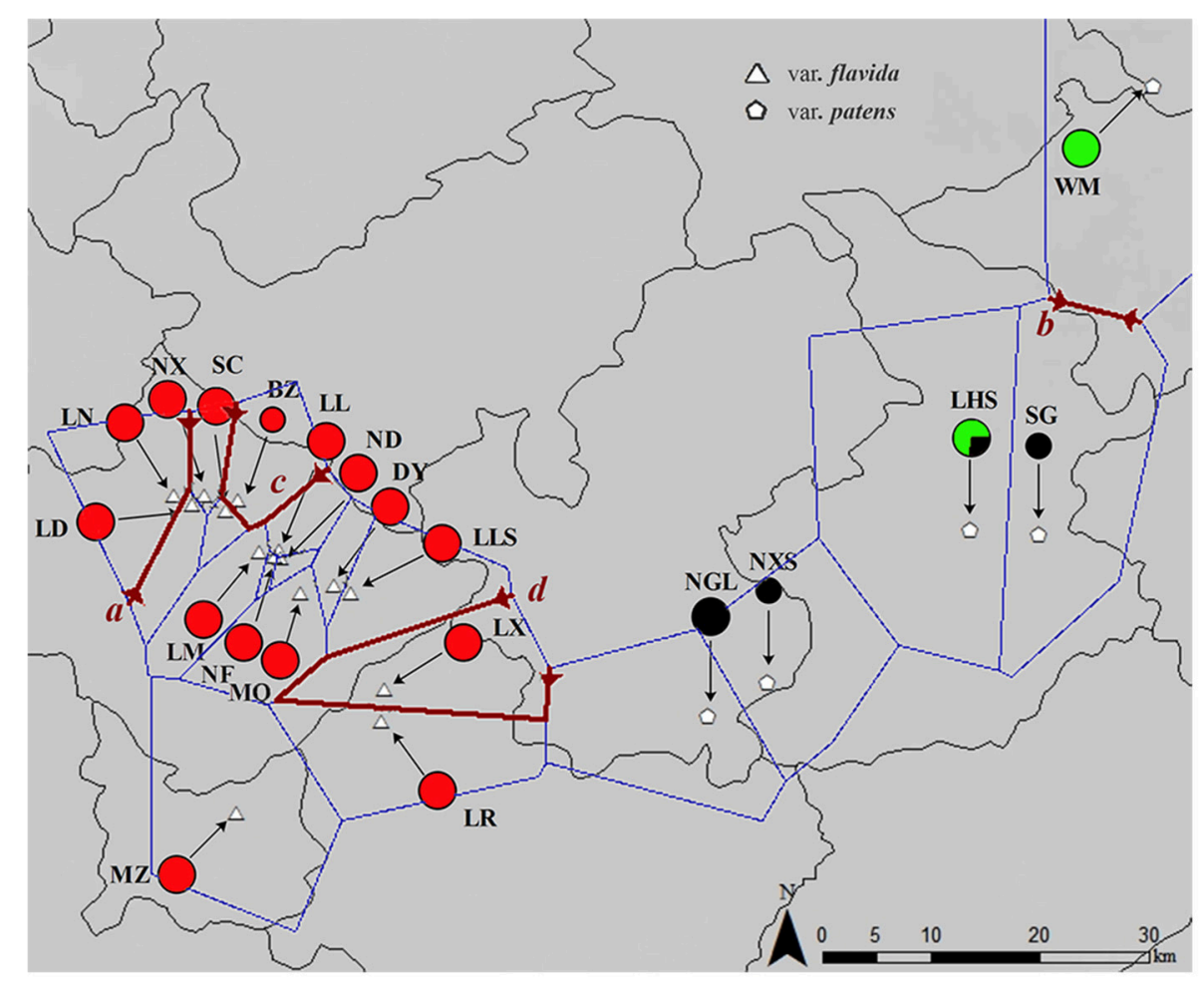

FIGURE 1 | Map of the sampling location and results of the barrier analyses. The colors of the populations represent the cpDNA haplotype lineages as identified by phylogenetic analyses. The first four barriers $a, b, c$, and $d$ defined by the Monmonier algorithm of the $P A L$ datasets are represented by dark red lines.

bromide (CTAB) method (Doyle and Doyle, 1987). This modification to the CTAB protocol included incubation for $2 \mathrm{~h}$ in a $65^{\circ} \mathrm{C}$ water bath.

\section{PCR Amplification and DNA Sequencing}

A chloroplast genome fragment from the small single-copy (SSC) region containing several genes was amplified using the following three primer pairs: SSC1, CP30 (Xi et al., 2012), and SSC3. PCR products were sequenced in both directions with the same primers and four internal sequencing primers (SSC1-1, CP30-1, CP30-2, and SSC3-1). The single-copy nuclear gene phenylalanine ammonia-lyase $(P A L)$ was amplified and sequenced using a primer design based on the sequences from Camellia taliensis (Liu et al., 2012). The sequences of primers used in this study are given in Table 3.

Both chloroplast and $P A L$ DNA fragments were amplified in $50 \mu \mathrm{L}$ reaction mixtures containing 30-50 ng genomic DNA, $5.0 \mu \mathrm{L}$ of $10 \times$ PCR buffer $\left(\mathrm{Mg}^{2+}\right.$ plus), $5 \mu \mathrm{L}$ of dNTP mix (10 mM), $0.5 \mu \mathrm{L}$ of each primer $(50 \mu \mathrm{M})$, and $2.5 \mathrm{U}$ of LA Taq DNA polymerase (all reagents, other than template DNA, from TaKaRa, China). DNA was amplified in a thermal cycler (Applied Biosystems, USA), programmed for an initial denaturation at $94^{\circ} \mathrm{C}$ for $3 \mathrm{~min}$; followed by 30 cycles of $30 \mathrm{~s}$ denaturation at $94^{\circ} \mathrm{C}, 30 \mathrm{~s}$ annealing at various annealing temperatures ( $\mathrm{Ta}$; Table 3), $1 \mathrm{~min}$ elongation at $72^{\circ} \mathrm{C}$; and an additional extension for $10 \mathrm{~min}$ at $72^{\circ} \mathrm{C}$. PCR products were purified and sequenced by Thermo Fisher Scientific (Guangzhou, China).

Previously reported karyotype analysis demonstrated that C. flavida is diploid $(2 n=30)$ (Zhang and Ming, 1995). $P A L$ sequence chromatograms containing double peaks at polymorphic sites were regarded as heterozygotes. For sequences with a single heterozygous site, we determined haplotypes using the method described by Clark (1990). For sequences with two or more additional peaks, the sequences of the two $P A L$ haplotypes were analyzed by cloning and sequencing of PCR amplicons. PAL fragments were amplified with the high-fidelity DNA polymerase (PrimeSTAR HS DNA Polymerase, TaKaRa, China). Cloned PCR products were purified and sequenced by Sangon Biotech (Shanghai, China). At least four clones were sequenced per PCR product (maximum eight clones). All haplotype sequences in this study were deposited in GenBank: KX751947-KX751960, KU669063, KU669073, KU669071, and KX751961-KX752048.

\section{Data Analyses}

DNA sequences were aligned using CLUSTAL X (Thompson et al., 1997) and edited manually in BioEdit7.0.1 where necessary (Hall, 1999). Insertions or deletions (indels) in cpDNA were treated as substitutions (single events) (Caicedo and Schaal, 2004). The degree of nucleotide substitution saturation for the $P A L$ gene was tested using DAMBE software (Xia and Lemey, 2009). 
TABLE 2 | Geographical location, sample size, and genetic diversity of $C$. flavida based on cpDNA and PAL sequences.

\begin{tabular}{|c|c|c|c|c|c|c|}
\hline $\begin{array}{l}\text { Population } \\
\text { code }\end{array}$ & $\begin{array}{l}\text { Latitude (N)/ } \\
\text { Longitude (E) }\end{array}$ & $\begin{array}{l}\text { Altitude } \\
\text { (m) }\end{array}$ & $\begin{array}{l}\text { Sample size } \\
\text { cpDNA (PAL) }\end{array}$ & $\begin{array}{c}\text { Number of haplotypes } \\
\text { cpDNA (PAL) }\end{array}$ & $\begin{array}{l}\text { Haplotype diversity } \\
\text { cpDNA (PAL) }\end{array}$ & $\begin{array}{c}\text { Nucleotide diversity } \\
\text { cpDNA (PAL) }\end{array}$ \\
\hline $\mathrm{MZ}$ & $106^{\circ} 52^{\prime} / 22^{\circ} 07^{\prime}$ & 343 & $10(10)$ & $1(5)$ & 0 (0.69474) & 0 (0.00642) \\
\hline LLS & $107^{\circ} 02^{\prime} / 22^{\circ} 25^{\prime}$ & 202 & $10(10)$ & $1(10)$ & $0(0.92105)$ & $0(0.00783)$ \\
\hline DY & $107^{\circ} 00^{\prime} / 22^{\circ} 25^{\prime}$ & 291 & $10(10)$ & $1(7)$ & $0(0.83684)$ & $0(0.00811)$ \\
\hline LL & $106^{\circ} 56^{\prime} 22^{\circ} 28^{\prime}$ & 191 & $10(10)$ & $1(9)$ & $0(0.90000)$ & $0(0.00580)$ \\
\hline ND & $106^{\circ} 56^{\prime} / 22^{\circ} 27^{\prime}$ & 247 & $10(10)$ & $1(8)$ & $0(0.84737)$ & $0(0.00640)$ \\
\hline LR & $107^{\circ} 04^{\prime} / 22^{\circ} 14^{\prime}$ & 215 & $10(10)$ & $1(6)$ & $0(0.79474)$ & $0(0.00418)$ \\
\hline LM & $106^{\circ} 54^{\prime} / 22^{\circ} 28^{\prime}$ & 213 & $10(10)$ & $1(6)$ & $0(0.77895)$ & $0(0.00685)$ \\
\hline LD & $106^{\circ} 49^{\prime} / 22^{\circ} 32^{\prime}$ & 234 & $10(10)$ & $1(9)$ & 0 (0.87895) & $0(0.00760)$ \\
\hline$M Q$ & $106^{\circ} 58^{\prime} / 22^{\circ} 25^{\prime}$ & 192 & $10(10)$ & $1(5)$ & $0(0.73158)$ & 0 (0.00732) \\
\hline $\mathrm{NF}$ & $106^{\circ} 55^{\prime} / 22^{\circ} 27^{\prime}$ & 176 & $10(10)$ & $1(5)$ & $0(0.73158)$ & $0(0.00587)$ \\
\hline NX & $106^{\circ} 50^{\prime} / 22^{\circ} 32^{\prime}$ & 252 & $10(10)$ & $1(5)$ & $0(0.66842)$ & $0(0.00640)$ \\
\hline SC & $106^{\circ} 51^{\prime} / 22^{\circ} 31^{\prime}$ & 357 & $10(10)$ & $1(10)$ & 0 (0.92105) & 0 (0.00968) \\
\hline var. flavida 1 & & & & $11(58)$ & 0.91036 (0.97242) & $0.00090(0.00874)$ \\
\hline$B Z$ & $106^{\circ} 52^{\prime} / 22^{\circ} 32^{\prime}$ & 257 & $6(6)$ & 1 (3) & 0 (0.59091) & 0 (0.00107) \\
\hline$L X$ & $107^{\circ} 04^{\prime} / 22^{\circ} 17^{\prime}$ & 152 & $10(9)$ & $1(6)$ & 0 (0.66667) & 0 (0.00269) \\
\hline LN & $106^{\circ} 47^{\prime} / 22^{\circ} 32^{\prime}$ & 368 & $10(10)$ & 1 (3) & 0 (0.57368) & 0 (0.00096) \\
\hline var. flavida 2 & & & & $3(9)$ & $0.67692(0.82449)$ & 0.00029 (0.00214) \\
\hline var. flavida & & & $146(145)$ & $14(67)$ & 0.92962 (0.97599) & $0.00092(0.00902)$ \\
\hline SG & $107^{\circ} 56^{\prime} / 22^{\circ} 29^{\prime}$ & 165 & $6(5)$ & $1(5)$ & $0(0.66667)$ & $0(0.00347)$ \\
\hline LHS & $107^{\circ} 51^{\prime} / 22^{\circ} 30^{\prime}$ & 162 & $10(10)$ & $2(5)$ & 0.46667 (0.82105) & 0.0009 (0.00571) \\
\hline NXS & $107^{\circ} 35^{\prime} / 22^{\circ} 18^{\prime}$ & 246 & $6(6)$ & $1(5)$ & $0(0.75758)$ & 0 (0.00306) \\
\hline NGL & $107^{\circ} 30^{\prime} / 22^{\circ} 15^{\prime}$ & 202 & $10(10)$ & $1(8)$ & $0(0.74737)$ & $0(0.00390)$ \\
\hline WM & $108^{\circ} 06^{\prime} / 23^{\circ} 05^{\prime}$ & 138 & $10(10)$ & 1 (3) & 0 (0.27895) & 0 (0.00044) \\
\hline var. patens & & & $42(41)$ & $3(21)$ & $0.66086(0.89852)$ & $0.00090(0.00455)$ \\
\hline Total & & & 188 (186) & 17 (87) & 0.94101 (0.97993) & 0.00157 (0.00880) \\
\hline
\end{tabular}

The global and population numbers of haplotypes (A), the gene diversity (h) (Nei, 1987), and the nucleotide diversity $(\pi)$ (Tajima, 1983) were calculated using DNAsp v5 (Librado and Rozas, 2009). The median-joining method (Bandelt et al., 1999) was used to construct networks with Network 5.0 (Fluxus Technology Ltd. at www.Fluxus-engineering.com). A postprocessing MP calculation was used to search for the shortest tree. Several values of the parameter $\varepsilon$ were explored, without significant changes in network topology. The topology presented was obtained at the default settings $(\varepsilon=5)$. The geographical distribution of populations was mapped using ArcMap GIS (ESRI, 2009).

Phylogenetic analyses of the identified haplotypes for each marker were performed. Maximum-likelihood (ML) tree generation and bootstrap analyses were performed with the program RAxML-HPC-SSE3 (Stamatakis, 2006). We found the best-scoring ML tree using a generalized time reversible plus gamma model of sequence evolution with 1,000 bootstrap replicates. Sequences of the cpDNA region of Camellia oleifera (JQ975031) and Camellia pitardii (KF156837) and nuclear sequences of C. taliensis H16 (JX161631) and H17 (JX161632) were used as outgroups for analysis of C. flavida.

The presence of phylogeographic structures was inferred by testing for significant differences between $G_{S T}$ and $N_{S T}$ using PermutCpSSR 1.2.1, with 1,000 permutations (Pons and Petit, 1996). Gene flow (Nm) calculated using DNAsp v5 was used to assess the degree of genetic differentiation between populations.

A spatial analysis of molecular variance (SAMOVA) was conducted with SAMOVA 2.0. This approach defines groups of populations that are geographically homogeneous and maximally differentiated from each other (Dupanloup et al., 2002). We tested values for $\mathrm{K}$ in the range of 2-19, and the initial condition was set to 100 with 10,000 iterations. The configuration with the largest associated $F_{C T}$ value after the 100 independent simulated annealing processes is retained as the best grouping of populations. In addition, for nuclear DNA data, analysis of the Monmonier's algorithm was implemented with the BARRIER 2.2 program, which identifies possible barriers to gene flow among the most differentiated groups of populations, creating a Delaunay triangulation network to connect adjacent populations and, consequently, a Voronoi tessellation set (Manni et al., 2004).

Analyses of molecular variance (AMOVA) (Excoffier et al., 1992) were conducted using Arlequin 3.1 (Excoffier et al., 2005). Populations were grouped into two varieties. In addition, we repeated the AMOVA analyses with three genetic groups identified in this study. We performed AMOVAs to quantify the genetic variation at three hierarchical levels: (i) among 


\begin{tabular}{|c|c|c|c|}
\hline Primer & Sequence $\left(5^{\prime}-3^{\prime}\right)$ & Source & $\mathrm{Ta}\left({ }^{\circ} \mathrm{C}\right)$ \\
\hline \multicolumn{4}{|c|}{ CHLOROPLAST MARKERS } \\
\hline SSC1-F & AAACAGAAGAGATCCGAGT & $\begin{array}{l}\text { Designed by } \\
\text { the authors }\end{array}$ & 51 \\
\hline SSC1-1 & AATAGGCTATACTGACTGAA & & \\
\hline SSC1-R & TGTTATTTGTGTGCCGTTC & & \\
\hline CP30-F & GTAGCAGCATGTATAAGAGCTGAA & Xi et al., 2012 & 57.5 \\
\hline CP30-1 & AGCCCACATACGACGAAGTT & & \\
\hline CP30-2 & TTATTAGTAGGTCGATGAG & & \\
\hline CP30-R & GCTACTCGGACTCGAACCGAGAT & & \\
\hline SSC3-F & AAATCTCTTTCAACCGGAA & $\begin{array}{l}\text { Designed by } \\
\text { the authors }\end{array}$ & 49 \\
\hline SSC3-1 & GATAGAACTATCCAGTTACA & & \\
\hline SSC3-R & GCTCTATITTGTTTATATTCGTC & & \\
\hline \multicolumn{4}{|c|}{ NUCLEAR MARKERS } \\
\hline PAL-F & CACGTTACCACATTCAGCAACA & $\begin{array}{l}\text { Designed by } \\
\text { the authors }\end{array}$ & 56 \\
\hline PAL-R & CCGCGAAACATCGATTAAGGG & & \\
\hline
\end{tabular}

populations, (ii) within populations, and (iii) among groups of populations identified by the three genetic clusters found in this study.

\section{RESULTS}

\section{Chloroplast DNA Sequence Variation}

Alignment of cpDNA sequences from 188 C. flavida produced a consensus sequence of 5,178 base pairs. Seventeen haplotypes were defined with 38 polymorphic sites, including 33 substitutions and five indels. Of the five detected indels, two were five base pairs, and the other three were six, seven, and 11 base pairs. Most haplotypes were observed in only one population (Table S1). Only one population (LHS) had two chorotypes (C_15, C_16), and no haplotypes were shared between the two varieties. Four haplotypes were shared by two populations: C_3 (LL, ND), C_15 (LHS, WM), C_16 (SG, LHS), and C_17 (NXS, NGL) (Table S1). Total haplotype and nucleotide diversities were 0.94101 and 0.00157 , respectively (Table 2 ). We did not observe sequence variation within populations, other than within cpDNA in the LHS population (Table 2).

Median-joining network analysis was used to determine the relationships among cpDNA haplotypes and demonstrated that the two varieties are separated from one another by numerous mutations (Figure 2I). In var. patens, five populations were fixed for three haplotypes (C_15, C_16, and C_17). Haplotype C_15 was separated from C_16 and C_17 by a minimum of eight mutational steps (Figure 2I). The other part of the network contained all other haplotypes, clustered into a relatively concentrated group derived from var. flavida specimens. The ML tree produced a haplotype phylogenetic relationship similar to the one produced by the network analysis (Figures 2II).

The SAMOVA revealed that the cpDNA dataset of $C$. flavida can be partitioned into three groups. $F_{C T}$ values increase slightly with $\mathrm{K}$. When $\mathrm{K}$ was greater or equal to 4 , at least one member of the group contained a single population of C. flavida, indicating that the group structure was disappearing. When $\mathrm{K}$ equaled 3, all var. flavida formed a group, and var. patens was separated into two groups (LHS and WM; SG, NXS and NGL) (Table S3).

The contribution of phylogenetic relationships between haplotypes to among-population differentiation was nonsignificant $\left(G_{S T}=0.976\right.$ and $N_{S T}=0.974, N_{S T}<G_{S T}$; $P>0.05)$. Low gene flow $(N m=0.01)$ among the $20 \mathrm{C}$. flavida populations was detected by the cpDNA sequences.

\section{Nuclear DNA Sequence Variation}

We calculated the average $I_{S S}$ for subsets of 4, 8, 16, 32 OTUs ( $I_{S S}=0.012,0.011,0.012$, and 0.013 , respectively) and found that they were significantly smaller than the corresponding $I_{S S . C}$ values $\left(I_{S S . C}=0.805,0.765,0.744\right.$, and 0.718 , respectively; $P=0.0000$ ), indicating that substitution in the $P A L$ gene region is not saturated. The alignment of $372 P A L$ gene sequences from 186 samples was 653 base pairs long and contained 52 parsimony informative sites, 17 single-nucleotide polymorphisms, and no indels, resulting in 87 distinct haplotypes (Table S2). Only one haplotype (H_67) was shared between var. flavida and var. patens. Each population contained both shared and unique haplotypes. Var. flavida had 67 haplotypes, 49 of which were unique. Var. patens had 21 haplotypes, of which 16 were unique and five were shared. WM was the only population with only unique haplotypes. Haplotype sharing usually occurred in adjacent populations, but some adjacent populations either did not share a haplotype at all (e.g., populations BZ and SC; populations LX and LR) or shared only very common haplotypes (e.g., populations DY and LLS). Total haplotype and nucleotide diversities were 0.97993 and 0.00880 , respectively (Table 2 ). Haplotype diversity $(h)$ ranged from 0.27895 to 0.92105 , and nucleotide diversity $(\pi)$ ranged from 0.00044 to 0.00968 (Table 2). The highest values of $\mathrm{h}$ and $\pi$ were found in population SC $(h=0.92105, \pi=0.00968)$, and the lowest were in population WM $(h=0.27895, \pi=$ 0.00044) (Table 2). Although levels of genetic diversity varied greatly, there is less obvious correlation between relationships measures of diversity in population level with geographical location.

In the SAMOVA analysis, $F_{C T}$ values increased progressively as $\mathrm{K}$ was increased. For the first three $F_{C T}$ values, the $F_{C T}$ value was highest when $K$ was 3 . When $K$ was between 4 and 19, each new group consisted of only a single population. Therefore, in our dataset, C. flavida populations can optimally be placed into three groups (Table S4). These three groups included group I (ND, MQ, NF, DY, LLS, LR, SC, NX, LM, LL, MZ, $\mathrm{LD}$, named var. flavida 1), group II (BZ, LX, LN, named var. flavida 2), and group III (SG, LHS, NXS, NGL, WM, named var. patens).

The $P A L$ haplotype network is presented in Figure 3. Haplotypes from var.patens (H_67 through H_87) were clustered together and situated in the middle of the network, separating haplotypes of var. flavida 1 (H_1-H_57, H_67) from those of var. flavida 2 (H_58-H_66). In the ML tree, although the bootstrap value was low, all the haplotypes of var. flavida 2 and 

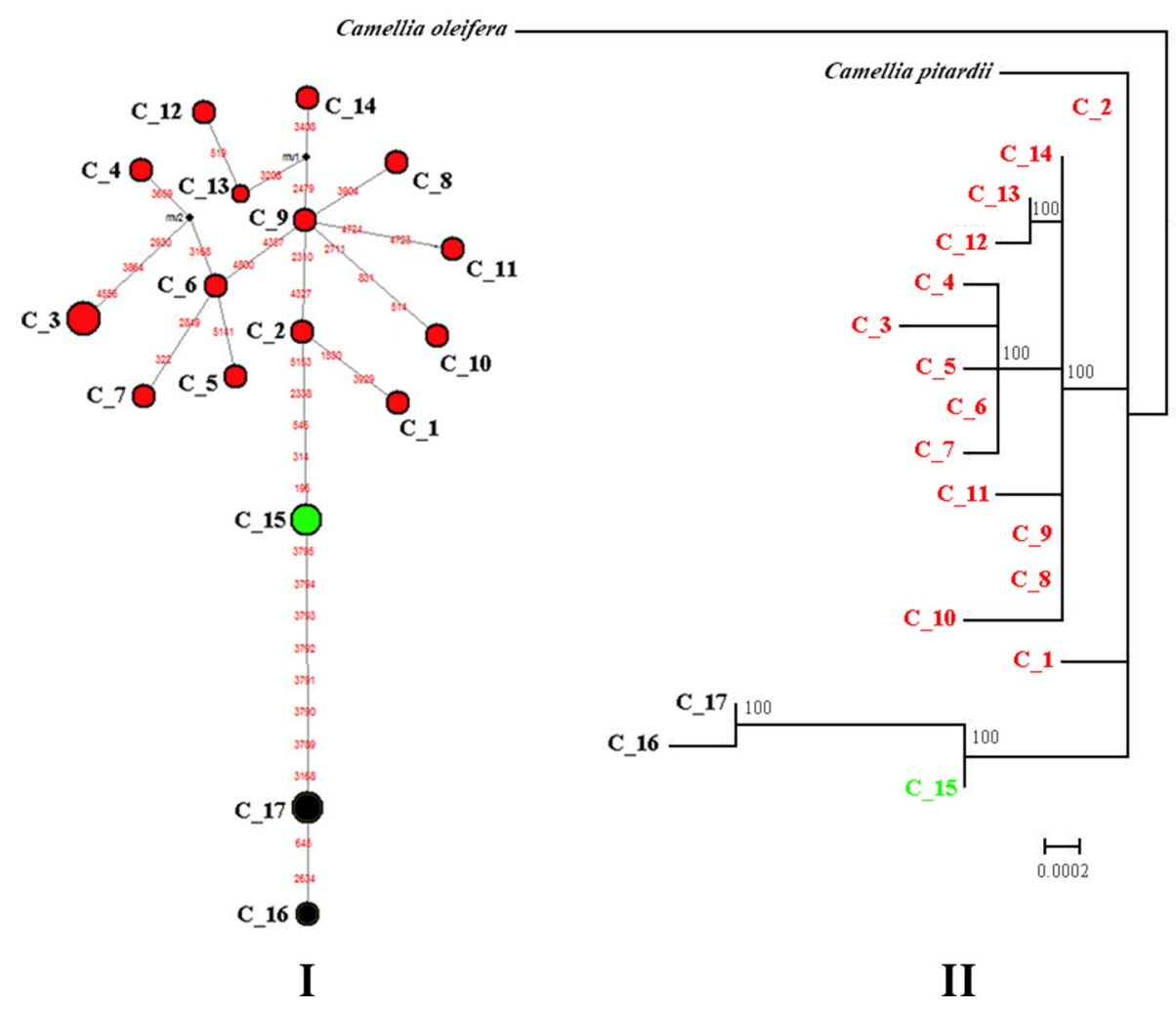

FIGURE 2 | Median-joining network (I) and Maximum Likelihood phylogenetic tree (II) showing the genetic relationships among the observed cpDNA haplotypes of C. flavida. (I) Median-joining network of 17 cpDNA haplotypes resolved in C. flavida. Each haplotype is designated by a number C_1 to C_17 (see Table S1). Colors denote the groups as identified by SAMOVA analyses of cpDNA marker. Circle size is proportional to haplotype frequency. Missing haplotypes are represented by black dots, and mutations are shown in red. (II) Maximum Likelihood tree. Numbers at nodes represent the result of the ML bootstrap analysis. Nodes without numbers correspond to supports weaker than $70 \%$ BP.

most haplotypes of var. patens clustered together respectively (Figure S1).

Our analyses of $P A L$ sequence data revealed a phylogeographic structure across all populations $\left(G_{S T}=0.253, N_{S T}=0.414\right.$; $\left.N_{S T}>G_{S T} ; P<0.05\right)$. Nm value $(0.35)$ detected by nuclear DNA sequences indicated that gene flow among populations was limited.

\section{AMOVA Analysis}

Over $60 \%$ of the genetic variation in cpDNA was attributable to variation among varieties; $57.95 \%$ of the variation was explained if the C. flavida populations were grouped into the three $P A L$ SAMOVA groups (Table 4). The within population variation was low (1.76 and $2.18 \%$ in two varieties and the three PAL SAMOVA groups (Table 4). In contrast to the chloroplast DNA results, the molecular difference between var. flavida and var. patens in the PAL data was low (17.81\%) and accounts for 53.28\% of the genetic variation within populations (Table 4). When the populations were partitioned into the three PAL SAMOVA groups, a similar level of variation (51.58\%) was observed within populations, but the variation among groups was much higher (31.19\%). Thus, three genetic groups might be optimal for these populations.
The number of haplotypes $(A)$, the haplotype diversity $(h)$, and the nucleotide diversity $(\pi)$ of each PAL SAMOVA group are shown in Table 2. The var. flavida 1 group had the highest level of genetic diversity (cpDNA: $A=11, h=0.91036, \pi=$ 0.00090; PAL: $A=58, h=0.97242, \pi=0.00874)$. The var. flavida 2 group (cpDNA: $A=3, h=0.67692, \pi=0.00029 ; P A L: A=9$, $h=0.82449, \pi=0.00214$ ) and var. patens (cpDNA: $A=3, h=$ 0.66086, $\pi=0.00090$; PAL: $A=21, h=0.89852, \pi=0.00455)$ have a relatively lower level of genetic diversity.

\section{Barrier to Gene Flow}

In the barrier analysis of the $P A L$ dataset (for graphical representation see Figures S2, S3 in Supplementary Material), we analyzed the first four barriers with (1) all populations and (2) the largest group (var. flavida 1). The Monmonier algorithm (barrier program) suggested four main barriers to gene flow in the distribution range of all populations (called $a$ through $d)$. Three barriers $(a, c$, and $d$ ) separate group var. flavida 2 populations (LN, BZ, and LX) from a group of var. flavida 1 populations (Figure 1). The second barrier (b) separates WM from SG (Figure 1). In the largest group (var. flavida 1), barriers were found in geographically close populations in addition to the barriers between distant populations (Figure S2). 


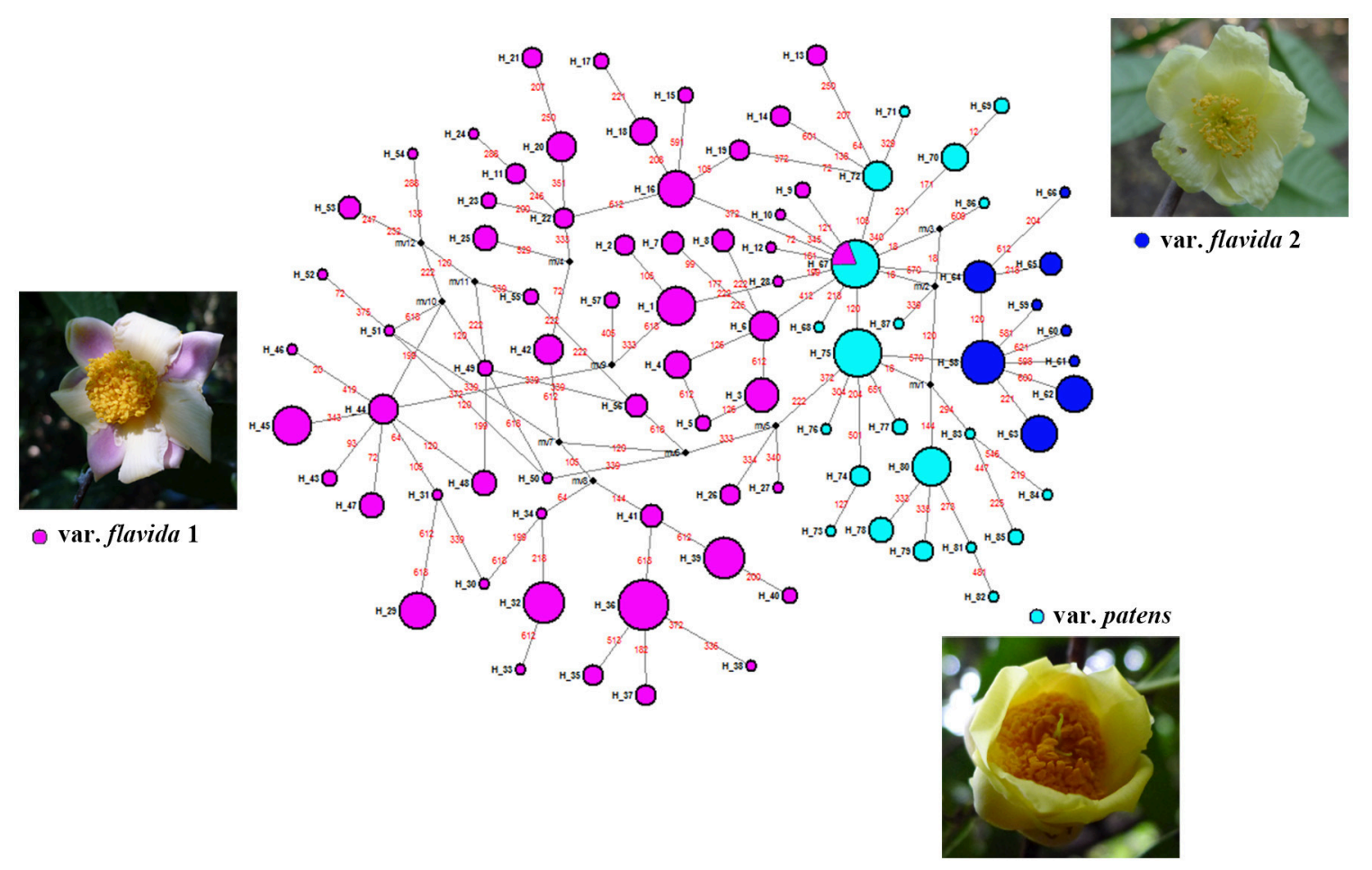

FIGURE 3 | Median-joining network for 87 PAL haplotypes and images of specimens of the three taxa identified in this study. Each haplotype is designated by a number H_1 to H_89 (see Table S2). Colors denote the groups as identified by SAMOVA analyses of PAL marker. Circle size is proportional to haplotype frequency. Missing haplotypes are represented by black dots, and mutations are shown in red.

\section{DISCUSSION}

\section{The Samples Collected Constitute Three Taxa}

According to nuclear DNA data, C. flavida is clustered into three genetic groups. These three groups are supported by the SAMOVA. Populations of var. patens formed a single genetic group. Haplotypes of the nuclear gene $P A L$ from var. patens were phylogenetically related (Figure 3), with only one haplotype shared with var. flavida. Populations of var. flavida include two groups, var. flavida 1 and var. flavida 2. Although the distribution of var. flavida 1 and var. flavida 2 is overlapping, there are barriers to gene flow between these two groups (Figure 1). These three genetic groups are consistent with their morphological characteristics. The morphological characteristics of flowers, fruits, seeds, and leaves of nine populations of var. flavida 1 were studied by Ye and Xue (2013). The inner petals of this variant are light yellow, and the outer layer is light yellow with red patches or purple-red streaks (var. flavida 1, Figure 3). The plants flower from July to November. The LN and LX populations of var. flavida 2, are morphologically different from those of var. flavida 1 . We found that the LN and LX petals were all light yellow, with no red or purple streaks or spots (var. flavida 2, Figure 3), and the plants mainly flowered from November to December. In addition, the shape of the leaves of var. flavida 2 is different from var. flavida 1, leading to the misidentification of var. flavida 2 as a different species by the administrator of Nonggang Nature Reserve, where these populations are located. According to the observations of Ye and Xue (2013), the petals of flowers from var. patens populations were all dark yellow, with no red or purple streaks or spots (Figure 3), and the plants flowered from January to February. In the SAMOVA analysis of chloroplast DNA sequences, the best value for $\mathrm{K}$ was three, but all var. flavida formed a group, and var. patens was separated into two groups. Similar results have been reported in many phylogeographic studies of closely related plant taxa. The distributions of chloroplast haplotypes frequently reveal geographic structure, and this geographic pattern may be incongruent with the current taxonomy (Rautenberg et al., 2010; Christe et al., 2014).

After combining molecular analyses and morphological observations, we concluded that the samples collected constitute three taxa, which is consistent with the three PAL groups. Samples from population BZ and the type herbarium specimens of $C$. flavida were collected from the same location; therefore, we suggest that var. flavida 2 is the genuine C. flavida.

\section{Genetic Diversity and Population Structure}

A high level of genetic diversity was observed at the species level in C. flavida. All measures of genetic diversity (haplotype numbers $=17$, haplotype diversity $=0.94101$, and nucleotide diversity $=0.00157$ for cpDNA; haplotype 
TABLE 4 | Analyses of molecular variance (AMOVA) based on cpDNA and nuclear DNA from $C$. flavida.

\begin{tabular}{|c|c|c|c|}
\hline \multirow[b]{2}{*}{ Grouping } & \multirow[b]{2}{*}{$\begin{array}{l}\text { Source of } \\
\text { variation }\end{array}$} & \multirow{2}{*}{$\begin{array}{l}\text { Chloroplast DNA } \\
\text { Percentage of } \\
\text { variation (\%) }\end{array}$} & \multirow{2}{*}{$\begin{array}{l}\text { Nuclear DNA } \\
\text { Percentage of } \\
\text { variation (\%) }\end{array}$} \\
\hline & & & \\
\hline \multirow[t]{3}{*}{ Varieties } & Among varieties & $63.46^{\star *}$ & $17.81^{\star \star}$ \\
\hline & $\begin{array}{l}\text { Among populations } \\
\text { within varieties }\end{array}$ & $34.78^{* \star}$ & $28.92^{* \star}$ \\
\hline & Within populations & $1.76^{\star \star}$ & $53.28^{\star \star}$ \\
\hline \multirow[t]{3}{*}{ SAMOVA groups } & Among groups & $57.95^{\star \star}$ & $31.19^{\star \star}$ \\
\hline & $\begin{array}{l}\text { Among populations } \\
\text { within groups }\end{array}$ & $39.87^{\star \star}$ & $17.23^{\star \star}$ \\
\hline & Within populations & $2.18^{\star \star}$ & $51.58^{\star \star}$ \\
\hline \multirow[t]{2}{*}{ var. flavida 1} & Among populations & $100.00^{\star \star}$ & $22.77^{\star \star}$ \\
\hline & Within populations & $0.00^{\star \star}$ & $77.23^{\star \star}$ \\
\hline \multirow[t]{2}{*}{ var. flavida 2} & Among populations & $100.00^{\star \star}$ & $32.90^{* \star}$ \\
\hline & Within populations & $0.00^{\star \star}$ & $67.10^{\star \star}$ \\
\hline \multirow[t]{2}{*}{ var. patens } & Among populations & $79.25^{* *}$ & $31.68^{\star \star}$ \\
\hline & Within populations & $20.75^{\star \star}$ & $68.32^{\star \star}$ \\
\hline
\end{tabular}

A priori groupings were: (1) two varieties of C. flavida and (2) three SAMOVA groups of $P A L$ marker, including var. flavida 1 (ND, MQ, NF, DY, LLS, LR, SC, NX, LM, LL, MZ, and $L D)$; var. flavida 2 (BZ, $L X$, and $L N)$; and var. patens (SG, LHS, NXS, NGL, and WM). ${ }^{\star \star} P<0.001$

numbers $=87$, haplotype diversity $=0.97993$, and nucleotide diversity $=0.00880$ for the $P A L$ gene) in C. flavida were higher than those in the congener, $C$. taliensis, which is believed to possess abundant variation (haplotype numbers = 12 , haplotype diversity $=0.84129$, and nucleotide diversity $=0.00314$ for cpDNA; haplotype numbers $=17$, haplotype diversity $=0.83639$, and nucleotide diversity $=0.00417$ for the PAL gene) (Liu et al., 2012). The number of $P A L$ haplotypes observed in this study was five times higher than those identified in C. taliensis. The increased variation has several possible sources. First, the sampled populations include three genetic groups or taxa (Chang, 1991; Chang and Ren, 1998). Second, mutations and limited gene flow may have produced numerous unique haplotypes. At the variety level, the genetic diversity of var. patens was lower than that of var. flavida, either because var. patens has a smaller distribution range, a more isolated distribution, or smaller population sizes.

This study of 20 populations of C. flavida across its entire known geographic range revealed a very strong genetic structure. The population differentiation estimated from cpDNA was very high $\left(G_{S T}=0.976\right.$ and $\left.N_{S T}=0.974\right)$, similar to plant species with the highest cpDNA differentiation (Petit et al., 2005). AMOVA analysis indicated that the among-groups variance is higher than that among populations within the two varieties. Chloroplast markers are haploid and are strictly maternally inherited in angiosperms (Birky, 2008). Therefore, they are expected to exhibit stronger genetic drift because their effective population size is lower than that of nuclear genes (Birky et al., 1983, 1989; Petit et al., 2005). In addition, substantial genetic differentiation of cpDNA may result from limited dispersal of heavy seeds that cannot travel long distances. We also discovered that many populations had low levels of genetic diversity in plastid DNA: Nineteen of the 20 analyzed populations were monomorphic (Table 2), suggesting an absence of gene flow through the movement of seeds $(\mathrm{Nm}=$ $0.01)$.

Population differentiation determined with the biparentally inherited nuclear PAL gene data was also high $\left(G_{S T}=0.253\right.$ and $\left.N_{S T}=0.414\right)$ compared with that in other angiosperm species (mean $G_{S T}=0.183$; Petit et al., 2005). The presence of significant phylogeographic structure was verified using the $P A L$ data $\left(G_{S T}<N_{S T}, P<0.05\right)$. AMOVA analysis indicated that most of the genetic diversity existed within populations (51.58\%), but the among-groups variance $(31.19 \%)$ is also very large. In our analysis of this nuclear marker, the gene flow $(\mathrm{Nm})$ among populations was 0.35 , and was primarily achieved by pollen transfer, given the lack of gene flow via seeds; however, gene flow between populations appears to be rather restricted. The mode of pollination and dispersal of $C$. flavida are poorly understood; however, bees are effective pollen vectors for its congeners Camellia oleifera (Deng et al., 2010) and Camellia japonica (Ueno et al., 2000). We also observed bees visiting $C$. flavida flowers during the field work for this study, and we suspect that bees may be important pollinators of C. flavida. The complex terrains of the karst provides a multitude of ecological niches and high habitat heterogeneity (Clements et al., 2006). Limestone karst landforms have been described as "terrestrial islands," which are isolated, island-like areas on restricted land masses (Gao et al., 2015). C. flavida grows only on limestone hills in depressions containing thick soil layers, which exhibit typical characteristics of terrestrial islands; therefore, distribution of C. flavida is fragmented, and its populations may be isolated from one another. In addition, such distributions can also make it difficult for pollinators to locate flowers, which limit dispersal ranges and forms potential barriers to gene flow. The third barriers were found in geographically close populations in group I identified by the SAMOVA. This may explain the high levels of genetic differentiation detected in C. flavida.

\section{Implications for Conservation}

Incorrect species classification can combine several distinct species into one, which can jeopardize the protection of endangered species (Frankham et al., 2002). Our genetic data clearly show that var. flavida includes two distinct taxa. These two taxa should be regarded as two management units to be managed separately. Control of illegal harvesting is critical for conservation of these species, and in situ conservation measures should be established first. In var. flavida 2, there are only three populations. Thus, populations of BZ, LX, and LN should be candidates for ex situ conservation.

Within var. patens, no haplotype is shared among the three distribution points (Table S2) and high genetic divergence was detected. Because the number of populations is limited and there 
are few individuals in each population, these populations (NXS, NGL, LHS, SG, and WM) are reasonable candidates for ex situ conservation in germplasm banks.

\section{CONCLUSIONS}

In our analysis of populations of a yellow Camellia species, we have found a high level of genetic differentiation and low gene flow attributable to the high habitat heterogeneity in limestone karst. There are three differentiated groups within the complex species. The detected genetic groups should be recognized as three conservation units.

\section{AUTHOR CONTRIBUTIONS}

YL and QY collected population samples. SW performed experiments, analyzed the data, and wrote the manuscript. ST designed the study and wrote and revised the manuscript. All authors have read and approved the final manuscript.

\section{FUNDING}

This study was supported by the National Natural Science Foundation of China (grant number 31260053) and Key Laboratory of Ecology of Rare and Endangered Species and Environmental Protection (Guangxi Normal University), Ministry of Education, China (grant number ERESEP2015Z01).

\section{REFERENCES}

Allendorf, F. W., and Luikart, G. (2007). Conservation and the Genetics of Populations. Malden, MA: Blackwell Publishing.

Avise, J. C. (2009). Phylogeography: retrospect and prospect. J. Biogeogr. 36, 3-15. doi: 10.1111/j.1365-2699.2008.02032.x

Bandelt, H. J., Forster, P., and Röhl, A. (1999). Median-joining networks for inferring intraspecific phylogenies. Mol. Biol. Evol. 16, 37-48. doi: 10.1093/oxfordjournals.molbev.a026036

Birky, C. W. Jr. (2008). Uniparental inheritance of organelle genes. Curr. Biol. 18, 613-627. doi: 10.1016/j.cub.2008.06.049

Birky, C. W., Maruyama, T., and Fuerst, P. (1983). An approach to population and evolutionary genetic theory for genes in mitochondria and chloroplasts, and some results. Genetics 103, 513-527.

Birky, C. W., Fuerst, P., and Maruyama, T. (1989). Organelle gene diversity under migration, mutation, and drift equilibrium expectations, approach to equilibrium, effects of heteroplasmic cells, and comparison to nuclear genes. Genetics 121, 613-627.

Caicedo, A. L., and Schaal, B. A. (2004). Population structure and phylogeography of Solanum pimpinellifolium inferred from a nuclear gene. Mol. Ecol. 13, 1871-1882. doi: 10.1111/j.1365-294X.2004.02191.x

Chang, H. T. (1981). A Taxonomy of the Genus Camellia. Guangzhou: Editorial Staff of the Journal of Sun Yatsen University.

Chang, H. D. (1991). A revision of the section Chrysantha of Camellia. Acta Sci. Nat. Univ. Sunyatseni 30, 76-84.

Chang, H. T., and Ren, S. X. (1998). “Theaceae," in Flora Reipublicae Popularis Sinicae, ed H. D. Chang (Beijing: Science Press), 107-110.

Christe, C., Caetano, S., Aeschimann, D., Kropf, M., Diadema, K., and Naciri, Y. (2014). The intraspecific genetic variability of siliceous and calcareous Gentiana species is shaped by contrasting demographic and re-colonization processes. Mol. Phylogenet. Evol. 70, 323-336. doi: 10.1016/j.ympev.2013.09.022

\section{ACKNOWLEDGMENTS}

We thank the Nonggang Nature Reserve and Chongzuo Whiteheaded Langur Nature Reserve for help in sample collection.

\section{SUPPLEMENTARY MATERIAL}

The Supplementary Material for this article can be found online at: http://journal.frontiersin.org/article/10.3389/fpls.2017. 00718/full\#supplementary-material

Figure S1 | Maximum Likelihood phylogenetic tree reconstruction for the C. flavida based on PAL sequences. Numbers at nodes represent the result of the ML bootstrap analysis. Nodes without numbers correspond to supports weaker than $70 \%$ BP. Double slashes on branches indicate branch length not in proportion.

Figure S2 | Delaunay triangulation and Voronoï tessellation of the barrier analyses for $\boldsymbol{C}$. flavida across the entire study area. Red points correspond to sampling sites. Barriers identified with the PAL dataset are dark red.

Figure S3 | Delaunay triangulation and Voronoï tessellation of the barrier analyses across a portion of the study area corresponding to populations containing individuals with the group (var. flavida 1) identified using PAL sequences. Red points correspond to sampling sites; barriers identified with the PAL dataset are dark red.

Table S1 | Chloroplast haplotype distribution of 20 C. flavida populations

Table S2 | PAL haplotype distribution of 20 C. flavida populations.

Table S3 $\mid F_{C T}$ values for different numbers of population groups (K) inferred by the SAMOVA algorithm using the cpDNA dataset.

Table S4 $F_{C T}$ values for different numbers of population groups (K) inferred by the SAMOVA algorithm using the PAL dataset.
Clark, A. G. (1990). Inference of haplotypes from PCR-amplified samples of diploid populations. Mol. Biol. Evol. 7, 111-122.

Clements, R., Sodhi, N. S., Schilthuizen, M., and Ng, P. K. (2006). Limestone karsts of Southeast Asia: imperiled arks of biodiversity. Bioscience 56, 733-742. doi: 10.1641/0006-3568(2006)56[733:LKOSAI]2.0.CO;2

Deng, Y. Y., Yu, X. L., and Luo, Y. B. (2010). The role of native bees on the reproductive success of Camellia oleifera in Hunan Province, Central South China. Acta Ecol. Sin. 30, 4427-4436.

Doyle, J. J., and Doyle, J. L. (1987). A rapid DNA isolation procedure for small quantities of fresh leaf tissue. Phytochem. Bull. 19, 11-15.

Dupanloup, I., Schneider, S., and Excoffier, L. (2002). A simulated annealing approach to define the genetic structure of populations. Mol. Ecol. 11, 2571-2581. doi: 10.1046/j.1365-294X.2002.01650.x,

E. S. R. I., E. (2009). ArcMap 9.2. Redlands, CA: ESRI.

Excoffier, L., Smouse, P. E., and Quattro, J. M. (1992). Analysis of molecular variance inferred from metric distances among DNA haplotypes application to human mitochondrial DNA restriction data. Genetics 131, 479-491.

Excoffier, L., Laval, G., and Schneider, S. (2005). Arlequin (version 3.0): an integrated software package for population genetics data analysis. Evol. Bioinform. Online 1, 47-50.

Frankel, O. H. (1974). Genetic conservation: our evolutionary responsibility. Genetics 78, 53-65.

Frankham, R., Ballou, J. D., and Briscoe, D. A. (2002). Introduction to Conservation Genetics. Cambridge: Cambridge University Press.

Gao, Y., Ai, B., Kong, H., Kang, M., and Huang, H. (2015). Geographical pattern of isolation and diversification in karst habitat islands: a case study in the Primulina eburnea complex. J. Biogeogr. 42, 2131-2144. doi: 10.1111/jbi.12576

Hall, T. A. (1999). BioEdit: a user-friendly biological sequence alignment editor and analysis program for Windows 95/98/NT. Nucl. Acids Symp. Ser. 41, 95-98.

Hao, Z., Kuang, Y., and Kang, M. (2014). Untangling the influence of phylogeny, soil and climate on leaf element concentrations in a 
biodiversity hotspot. Funct. Ecol. 29, 165-176. doi: 10.1111/1365-2435. 12344

He, D. Y., Li, X. Y., Wang, L. L., Zhang, P., Li, S. Y., and Xu, Y. P. (2016). Chemical constituents and pharmacological effects of Camellia nitidissima. Chin. J. Exp. Tradit. Med. Form. 22, 231-234.

Hong, D. Y. (2016). Biodiversity pursuits need a scientific and operative species concept. Biodivers. Sci. 24, 979-999. doi: 10.17520/biods.2016203

Leuzinger, M., Naciri, Y., Du Pasquier, P. E., and Jeanmonod, D. (2015). Molecular diversity, phylogeography and genetic relationships of the Silene paradoxa group of section Siphonomorpha (Caryophyllaceae). Plant Syst. Evol. 301, 265-278. doi: 10.1007/s00606-014-1071-3

Liang, S. Y. (1984). Two new species of Camellia from Guangxi, China. Bull. Bot. Res. 4, 185-186.

Liang, S. Y. (1993). Yellow Camellia. Beijing: China Forestry Publishing House.

Liang, S. Y. (2007). The world list of camellia. Guangxi Forestry Sci. 36, 221-223. doi: 10.3969/j.issn.1006-1126.2007.04.013

Liang, C. F., and Mo, X. L. (1982). Materials for the flora of Longgang conservation area, Guangxi. Guihaia 2, 61-67.

Librado, P., and Rozas, J. (2009). DnaSP v5: a software for comprehensive analysis of DNA polymorphism data. Bioinformatics 25, 1451-1452. doi: 10.1093/bioinformatics/btp187

Liu, Y., Yang, S. X., Ji, P. J., and Gao, L. Z. (2012). Phylogeography of Camellia taliensis (Theaceae) inferred from chloroplast and nuclear DNA: insights into evolutionary history and conservation. BMC Evol. Biol. 12:92. doi: 10.1186/1471-2148-12-92

Luo, Z., Tang, S., Jiang, Z., Jing, C., Fang, H., and Li, C. (2016). Conservation of terrestrial vertebrates in a global hotspot of karst area in Southwestern China. Sci. Rep. 6:25717. doi: 10.1038/srep25717

Manni, F., Guerard, E., and Heyer, E. (2004). Geographic patterns of (genetic, morphologic, linguistic) variation: how barriers can be detected by using Monmonier's algorithm. Hum. Biol. 76, 173-190. doi: 10.1353/hub.2004.0034

Ming, T. L. (2000). Monograph of the Genus 'Camellia.' Kunming: Yunnan Science and Technology Press.

Ming, T. L., and Bartholomew, B. (2007). “Theaceae," in Flora of China, eds Z. Y. Wu and P. H. Raven (Beijing: Science Press), 371.

Ming, T. L., and Zhang, W. J. (1993). On taxonomic problems of sect. Archecamellia Sealy and sect. Chrysantha Chang in the genus Camellia. Act. Bot. Yunnanica 15, 1-15.

Mkare, T. K., van Vuuren, B. J., and Teske, P. R. (2017). Conservation implications of significant population differentiation in an endangered estuarine seahorse. Biodivers. Conserv. 26, 1-19. doi: 10.1007/s10531-017-1300-5

Mo, X. L., and Zhong, Y. C. (1985). New taxa of section Chrysantha Chang from Guangxi. Guihaia 5, 353-356.

Nei, M. (1987). Molecular Evolutionary Genetics. New York, NY: Columbia University Press.

Orme, C. D., Davies, R. G., Burgess, M., Eigenbrod, F., Pickup, N., Olson, V. A., et al. (2005). Global hotspots of species richness are not congruent with endemism or threat. Nature 436, 1016-1019. doi: 10.1038/nature03850

Pérez-Espona, S., and Consortium, C. (2017). Conservation genetics in the European Union-Biases, gaps and future directions. Biol. Conserv. 209, 130-136. doi: 10.1016/j.biocon.2017.01.020

Petit, R. J., Duminil, J., Fineschi, S., Hampe, A., Salvini, D., and Vendramin, G. G. (2005). Comparative organization of chloroplast, mitochondrial and nuclear diversity in plant populations. Mol. Ecol. 14, 689-701. doi: 10.1111/j.1365-294X.2004.02410.x
Pons, O., and Petit, R. J. (1996). Measuring and testing genetic differentiation with ordered versus unordered alleles. Genetics 144, 1237-1245.

Rautenberg, A., Hathaway, L., Oxelman, B., and Prentice, H. C. (2010). Geographic and phylogenetic patterns in Silene section Melandrium (Caryophyllaceae) as inferred from chloroplast and nuclear DNA sequences. Mol. Phylogenet. Evol. 57, 978-991. doi: 10.1016/j.ympev.2010.08.003

Stamatakis, A. (2006). RAxML-VI-HPC: maximum likelihood-based phylogenetic analyses with thousands of taxa and mixed models. Bioinformatics 22, 2688-2690. doi: 10.1093/bioinformatics/btl446

Su, Z. M. (1994). A preliminary study on the population ecology of Camellia sect. nitidissima. Guangxi Sci. 1, 31-36.

Su, Z. M., and Mo, X. L. (1988). Geographic distribution of Camellia section Chrysantha from China. Guihaia 8, 75-81.

Su, Z., Richardson, B. A., Zhuo, L., and Jiang, X. (2017). Divergent population genetic structure of the endangered Helianthemum (Cistaceae) and its implication to conservation in Northwestern China. Front. Plant Sci. 7:2010. doi: $10.3389 /$ fpls.2016.02010

Tajima, F. (1983). Evolutionary relationship of DNA sequences in finite populations. Genetics 105, 437-460.

Thompson, J. D., Gibson, T. J., Plewniak, F., Jeanmougin, F., and Higgins, D. G. (1997). The CLUSTAL_X windows interface: flexible strategies for multiple sequence alignment aided by quality analysis tools. Nuc. Acid. Res. 25, 4876-4882. doi: 10.1093/nar/25.24.4876

Ueno, S., Tomaru, N., Yoshimaru, H., and Manabe, T. (2000). Genetic structure of Camellia japonica L. in an old-growth evergreen forest, Tsushima, Japan. Mol. Ecol. 9, 647-656. doi: 10.1046/j.1365-294x.2000.00891.x

Wang, S., and Xie, Y. (2004). China Species Red List, Vol. 1. Beijing: Higher Education Press.

Wang, S. J., Liu, Q. M., and Zhang, D. F. (2004). Karst rocky desertification in Southwestern China: geomorphology, landuse, impact and rehabilitation. Land Degrad. Dev. 15, 115-121. doi: 10.1002/ldr.592

Xi, Z., Ruhfel, B. R., Schaefer, H., Amorim, A. M., Sugumaran, M., Wurdack, K. J., et al. (2012). Phylogenomics and a posteriori data partitioning resolve the Cretaceous angiosperm radiation Malpighiales. Proc. Natl. Acad. Sci. U.S.A. 109, 17519-17524. doi: 10.1073/pnas.1205818109

Xia, X., and Lemey, P. (2009). Assessing substitution saturation with DAMBE. Phylogenetic 2, 615-630. doi: 10.1017/CBO9780511819049.022

Ye, Q. Q., and Xue, Y. G. (2013). Comparisions of morphological characters of some Camellia species which were reduced to Camellia flavida H. T. Chang and discussion on their taxonomic status. Act. Sci. Nat. Univ. Sunyatseni 52:20. doi: 10.13471/j.cnki.acta.snus.2013.03.015

Yuan, D. (1991). Karst of China. Beijing: Geological Publishing House.

Zhang, W. J., and Ming, T. L. (1995). Karyotypical study of sect. Archecamellia of genus Camellia. Act. Bot. Yunnanica 17, 48-54.

Conflict of Interest Statement: The authors declare that the research was conducted in the absence of any commercial or financial relationships that could be construed as a potential conflict of interest.

Copyright (C) $2017 \mathrm{Wei}, \mathrm{Lu}, \mathrm{Ye}$ and Tang. This is an open-access article distributed under the terms of the Creative Commons Attribution License (CC BY). The use, distribution or reproduction in other forums is permitted, provided the original author(s) or licensor are credited and that the original publication in this journal is cited, in accordance with accepted academic practice. No use, distribution or reproduction is permitted which does not comply with these terms. 